\title{
Helmet use and risk of head injuries in alpine skiers and snowboarders: changes after an interval of one decade
}

\author{
Steinar Sulheim, ${ }^{1,2}$ Arne Ekeland, ${ }^{3}$ Ingar Holme, ${ }^{2}$ Roald Bahr ${ }^{2}$
}

${ }^{1}$ Orthopaedic Department, Gjoevik hospital, SIHF, Gjøvik, Norway

${ }^{2}$ Oslo Sports Trauma Research Center, Norwegian School of Sport Sciences, Oslo, Norway ${ }^{3}$ Martina Hansens Hospital, Baerum, Norway

\section{Correspondence to} Dr Steinar Sulheim, Orthopaedic Department, Gjoevik hospital, SIHF, Kyrre Grepps gate 11, Gjøvik 2819, Norway; steinar.sulheim@ sykehuset-innlandet.no

Accepted 3 July 2016 Published Online First 16 August 2016
CrossMark

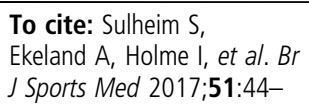

\begin{abstract}
Background In a previous study, we concluded that a safety helmet can reduce the risk for head injury by $60 \%$. Other studies reported similar effects, resulting in a general recommendation to wear a helmet while skiing or snowboarding.
\end{abstract}

Aim To determine the effect of the expected increased helmet wear on the risk of head injury one decade after the recommendation.

Methods Ski patrols reported injury cases in major Norwegian alpine ski resorts. Injury type, helmet use and other risk factors were recorded. A multiple logistic regression analysis was used to assess the relation between individual risk factors and the risk of head injuries by comparing head injured skiers (cases) with skiers and snowboarders who reported other injuries (controls).

Results Helmet use was associated with improved odds for head injuries (OR: $0.45,95 \% \mathrm{Cl} 0.34$ to 0.60 ; $p<0.001$ ) in 2002; this effect was attenuated in 2010 (OR: $0.79,95 \% \mathrm{Cl} 0.63$ to $0.98 ; p=0.02$ ), and not significant in 2011 (OR: 0.80, 95\% Cl 0.60 to 1.06; $p=0.12$ ). For potentially severe head injuries, the protective effect of using a helmet was better sustained over the observation period, from an OR of $0.44(95 \%$ $\mathrm{Cl} 0.28$ to $0.68, p<0.001)$ in 2002 to an OR of 0.74 $(95 \% \mathrm{Cl} 0.57$ to $0.97, \mathrm{p}=0.02)$ in 2010 and 0.67 (95\% Cl 0.47 to $0.96 ; p=0.03$ ) in 2011.

Conclusions We observed an unexpected reduction in the protective effect of a skiing helmet. This may be due to new skiing trends in the alpine resorts.

\section{INTRODUCTION}

Helmet use in alpine skiing and snowboarding has been a contentious issue for many years. Haid first introduced the issue of wearing a safety helmet while skiing in $1955 .{ }^{1}$ Mandatory helmet use for children up to 17 years was first advocated in 1983. ${ }^{2}$ Still, helmet use among adults did not become common until the current decade, after several studies had led to the same conclusion that head injury risk among skiers and snowboarders is reduced by wearing a helmet and with no evidence of increased risk of neck injury. ${ }^{3-8}$

In 2005, Hagel et al ${ }^{4}$ reported a $29 \%$ reduction in head injury risk for skiers and snowboarders wearing a helmet at 19 ski areas in Quebec, Canada. On the basis of a case-control study in eight major Norwegian alpine resorts during the 2002 winter season, comparing 3277 injured skiers and snowboarders with 2992 non-injured controls, we concluded that using a helmet was associated with a $60 \%$ reduction in the risk for head injury
(57\% for severe head injuries). ${ }^{3}$ In 2008 , Mueller et $a l^{9}$ reported a $15 \%$ reduction in head injuries with helmet use. Another study looked at head, face and neck injuries among children, and found an increased risk among those who did not wear a helmet. ${ }^{5}$ A retrospective cohort study by Greve et $a l^{10}$ showed a 5.8 -fold decreased incidence in loss of consciousness when hitting the head when using a skiing helmet. Rhugani et al, ${ }^{11}$ in a retrospective study of skiers with skull fractures, reported that the risk of a skull fracture was 10.5 -fold higher among those not wearing a helmet compared with helmet users. On the basis of selfreported injury data from 2986 neck injured skiers and snowboarders in Quebec covering the period from 1995-1996 to 2004-2005, Hagel et al ${ }^{12}$ concluded that helmets did not increase the risk of neck injuries or cervical spine fractures in skiers and snowboarders. On the basis of the above studies, recent reviews have also concluded that safety helmets decrease the risk and severity of head injuries in alpine skiing and snowboarding by roughly $40 \%$, without increasing the risk of neck injuries or risk-taking behaviour. ${ }^{6713}$

According to the 2012/2013 National Ski Areas Association (NSAA) National Demographic Study, $70 \%$ of skiers and snowboarders wore helmets, a dramatic increase from the 2002/2003 season, when only $25 \%$ wore helmets. ${ }^{14}$ We therefore wanted to repeat our study on Norwegian skiers and snowboarders, ${ }^{3}$ expecting to find a similar increase in the proportion of helmet users and hypothesising that, as a consequence, there would be a substantial reduction in head injuries.

\section{METHODS}

Ski patrols at major Norwegian ski resorts registered injuries during the 2002, 2010 and 2011 winter seasons. This study was based on anonymised data from the Norwegian Ski Lift Association injury and marketing research databases.

An injury was recorded when a skier or snowboarder was treated by or consulted the ski patrol or first aid room staff after an injury in the skiing/ snowboarding area during skiing/snowboarding or lift transport. To qualify for the ski patrol, the personnel are required to go through a structured programme of first aid education. A standard form was used to record personal data (age, gender, nationality), as well as information about equipment used (alpine skis, telemark skis (turning with free heel lift), snowboard, sleigh or other), the use of helmet (yes/no), rented or own equipment (yes/no), previous ski school attendance (yes/no) and skiing 
ability. Skiing ability was classified into four categories (beginner, intermediate, good or expert) based on self-reported performance of turns. 1

In addition, recordings were made of whether the injury occurred on the prepared piste, in park areas (terrain parks, areas within the ski resort with jumps, rails, obstacles), off-piste (outside groomed runs) or while taking the ski lift. The anatomical location (ranked from highest to lowest: head, neck, back, chest/tummy, shoulder, arm, wrist, hand, thigh, knee, leg, ankle, foot) and injury type (fracture, sprain, contusion, skin wound, illness) was recorded, as well as whether the patient needed further evaluation and treatment by physician or at a hospital, as assessed by the ski patrol. We defined such patients as potentially severe cases. Facial injuries were included among head injuries, while neck injuries represented a separate category. In cases with multiple injuries to the same person, only the highest ranked injury was recorded. In head injury cases with multiple injuries, we always ranked the head injury as the most severe.

Cases were skiers with injuries to the head, while as controls we used skiers and snowboarders who reported other injuries than head injuries (ie, arm, leg, trunk) at the same ski area in the same year. Fisher's exact tests were used to compare characteristics between groups. We used logistic regression analysis to estimate the relationship between helmet use and head injuries. To select potential confounders, we performed univariate analyses of the relationships to both head injuries and helmet use. Factors with $\mathrm{p}<0.20$ were used as adjustment factors for potential confounding in the logistic models. Owing to the large number of outcomes, it was not necessary to limit the number of variables in the model. A test of interaction between helmet use and study year was performed by adding a cross product term between the two variables together with the two linear terms, adjusting for the other covariates. In addition, we performed individual logistic regression analyses with and without each individual potential confounder to estimate the effect on the helmet use estimate on head injury risk, and we included confounders where the coefficient was $10 \%$ or more. A Wald test was used for significance testing. We used SPSS (V.22.0. Armonk, New York, USA) for the analyses. ORs are presented with their $95 \%$ CIs. A two-sided $\alpha$ level of 0.05 was considered statistically significant.

\section{RESULTS}

We recorded 11108 injured persons, 3276 in 2002, 4396 in 2010 and 3436 in 2011. In 2002, 17.6\% of these were head injuries and we observed a $13.1 \%$ relative reduction in the proportion of head injuries to $15.3 \%$ in 2010 ( $p<0.01$ vs 2002) and $15.4 \%$ in $2011(\mathrm{p}<0.05$ vs 2002) (table 1$)$. During the same decade, helmet use increased substantially among injured skiers and snowboarders, from $23.8 \%$ in 2002 to $68.1 \%$ in 2010 ( $p<0.001$ vs 2002 ) and $77.1 \%$ in 2011 ( $p<0.001$ vs 2002).

Table 1 shows the distribution of injuries in relation to other candidate risk factors in 2002, 2010 and 2011. The proportion of injured skiers and snowboarders who defined themselves as experts increased from 2002 to 2010 ( $p<0.01$ vs 2002) and 2011 ( $p<0.01$ vs 2002). In addition, a greater proportion of injuries occurred in park areas in 2010 ( $p<0.001$ vs 2002) and 2011 ( $p<0.001$ vs 2002). There were also changes in the equipment used with a greater proportion of injured alpine skiers in 2010 ( $p<0.01$ vs 2002) and 2011 ( $p<0.01$ vs 2002). In the same period, the proportion of injured snowboarders was reduced $(\mathrm{p}<0.001$ vs 2002 in $2010, \mathrm{p}<0.001$ vs 2002 in 2011), as was that of injured telemark skiers ( $p<0.01$ vs 2002 in $2010, p<0.01$ vs 2002 in 2011). Apart from these changes,
Table 1 Distribution of characteristics associated with injured skiers and snowboarders in 2002, 2010 and 2011

\begin{tabular}{|c|c|c|c|c|c|c|}
\hline & \multicolumn{2}{|c|}{$2002(n=3276)$} & \multicolumn{2}{|c|}{$2010(n=4396)$} & \multicolumn{2}{|c|}{$2011(n=3436)$} \\
\hline & $\mathrm{n}$ & Per cent & $\mathbf{n}$ & Per cent & $\mathrm{n}$ & Per cent \\
\hline \multicolumn{7}{|l|}{ Helmet use } \\
\hline Yes & 780 & 23.8 & 2992 & 68.1 & 2650 & 77.1 \\
\hline No & 2443 & 74.6 & 1000 & 22.7 & 647 & 18.9 \\
\hline Unknown & 53 & 1.6 & 404 & 9.2 & 139 & 4.0 \\
\hline \multicolumn{7}{|l|}{ Age } \\
\hline$<13$ & 453 & 13.8 & 682 & 15.5 & 565 & 16.5 \\
\hline $13-20$ & 1392 & 42.5 & 1540 & 35.0 & 1430 & 41.7 \\
\hline$>20$ & 1393 & 42.5 & 1839 & 41.8 & 1305 & 38.1 \\
\hline Unknown & 38 & 1.2 & 335 & 7.6 & 128 & 3.7 \\
\hline \multicolumn{7}{|l|}{ Gender } \\
\hline Male & 1965 & 60.0 & 2626 & 59.7 & 2140 & 62.4 \\
\hline Female & 1281 & 39.1 & 1654 & 37.6 & 1273 & 37.1 \\
\hline Unknown & 30 & 0.9 & 116 & 2.6 & 15 & 0.4 \\
\hline \multicolumn{7}{|l|}{ Nationality } \\
\hline Norwegian & 1717 & 52.4 & 2248 & 51.1 & 1926 & 56.5 \\
\hline Swedish & 634 & 19.4 & 675 & 15.4 & 472 & 13.9 \\
\hline Danish & 661 & 20.2 & 908 & 20.7 & 685 & 20.1 \\
\hline Other & 260 & 7.9 & 418 & 9.5 & 324 & 9.5 \\
\hline Unknown & 4 & 0.1 & 147 & 3.3 & 29 & 0.8 \\
\hline \multicolumn{7}{|l|}{ Ability } \\
\hline Expert & 448 & 13.3 & 723 & 16.4 & 553 & 16.1 \\
\hline Good & 946 & 28.9 & 1166 & 26.5 & 1076 & 31.4 \\
\hline Intermediate & 963 & 29.4 & 1284 & 29.2 & 979 & 28.6 \\
\hline Beginner & 846 & 25.8 & 829 & 18.9 & 671 & 19.6 \\
\hline Unknown & 73 & 2.2 & 394 & 9.0 & 149 & 4.3 \\
\hline \multicolumn{7}{|l|}{ Location } \\
\hline On piste & 2468 & 75.3 & 2557 & 58.2 & 2063 & 60.2 \\
\hline Off-piste & 312 & 9.5 & 429 & 9.8 & 316 & 9.2 \\
\hline Park area & 262 & 8.0 & 911 & 20.7 & 841 & 24.5 \\
\hline Lift & 142 & 4.4 & 140 & 3.2 & 113 & 3.2 \\
\hline Unknown & 92 & 2.8 & 298 & 6.8 & & 2.0 \\
\hline \multicolumn{7}{|l|}{ Equipment } \\
\hline Alpine & 1607 & 49.1 & 2753 & 62.6 & 2330 & 68.8 \\
\hline Snowboard & 1391 & 42.5 & 1183 & 26.9 & 948 & 27.7 \\
\hline Telemark & 179 & 5.5 & 97 & 2.2 & 60 & 1.8 \\
\hline Unknown & 93 & 2.8 & 288 & 6.6 & 28 & 0.8 \\
\hline
\end{tabular}

only minor differences were observed over the years in the distribution of other characteristics (table 1).

Table 2 shows the univariate relationship between head injuries and each of the candidate risk factors in 2002, 2010 and 2011. Head injuries were less common among those wearing a helmet than those not wearing a helmet in 2002 (OR: 0.57, $95 \%$ CI 0.45 to $0.73, \mathrm{p}<0.001)$; this difference was less pronounced in 2010 (OR: $0.82,95 \%$ CI 0.68 to $0.99, \mathrm{p}<0.05$ ) and 2011 (OR: $0.90,95 \%$ CI 0.77 to $1.11, \mathrm{p}=0.21$ ). There was a continuing gender difference with favourable odds for females (OR: 0.70 in 2002, 95\% CI 0.58 to $0.85, \mathrm{p}<0.001$; OR: 0.82 in $2010,95 \%$ CI 0.68 to $0.98, p=0.03$; OR: 0.80 in 2011, $95 \%$ CI 0.66 to $0.98, p=0.03)$. Experienced skiers and snowboarders had greater odds of being head injured in 2002 (OR: 1.43, 95\% CI 1.18 to $1.72, \mathrm{p}<0.001$ ), 2010 (OR: 1.22, 95\% CI 1.03 to $1.47, \mathrm{p}=0.03$ ) and 2011 (OR: $1.25,95 \%$ CI 1.02 to $1.52, \mathrm{p}=0.03)$. Previous skiing instruction was not associated with the proportion of head injuries at any time. 
Table 2 Univariate comparison of relationship between candidate risk factors and head injuries

\begin{tabular}{|c|c|c|c|c|c|c|c|c|c|c|c|c|}
\hline & \multicolumn{4}{|c|}{$2002(578 / 3276)$} & \multicolumn{4}{|c|}{$2010(673 / 4396)$} & \multicolumn{4}{|c|}{$2011(530 / 3436)$} \\
\hline & $\begin{array}{l}\text { Head injured } \\
\text { (n) }\end{array}$ & $\begin{array}{l}\text { Controls } \\
\text { (n) }\end{array}$ & $\begin{array}{l}\text { Per } \\
\text { cent }\end{array}$ & $\mathrm{p}$ Value & $\begin{array}{l}\text { Head injured } \\
\text { (n) }\end{array}$ & $\begin{array}{l}\text { Controls } \\
\text { (n) }\end{array}$ & $\begin{array}{l}\text { Per } \\
\text { cent }\end{array}$ & $p$ Value & $\begin{array}{l}\text { Head injured } \\
\text { (n) }\end{array}$ & $\begin{array}{l}\text { Controls } \\
\text { (n) }\end{array}$ & $\begin{array}{l}\text { Per } \\
\text { cent }\end{array}$ & p Value \\
\hline Helmet use & & & & $<0.001$ & & & & 0.03 & & & & 0.21 \\
\hline Yes & $96(17)$ & $684(26)$ & 12.3 & & $455(72)$ & 2487 (76) & 15.5 & & $400(79)$ & $2206(87)$ & 15.3 & \\
\hline No & 476 & 1967 & 19.5 & & 179 & 806 & 18.2 & & 107 & 534 & 16.7 & \\
\hline Age & & & & 0.85 & & & & 0.72 & & & & 0.65 \\
\hline$<13$ & $78(67)$ & $375(70)$ & 17.2 & & $112(90)$ & $552(95)$ & 16.9 & & $90(91)$ & $468(96)$ & 16.1 & \\
\hline $13-20$ & $249(12)$ & $1143(22)$ & 17.9 & & $234(73)$ & $1273(75)$ & 15.5 & & $219(87)$ & 1195 (84) & 15.5 & \\
\hline$>20$ & $237(5)$ & $1156(15)$ & 17.0 & & $291(53)$ & 1509 (66) & 16.2 & & $196(60)$ & $1088(66)$ & 15.3 & \\
\hline Gender & & & & $<0.001$ & & & & 0.03 & & & & 0.01 \\
\hline Male & 385 (19) & $1580(29)$ & 19.6 & & $437(72)$ & $2139(75)$ & 17.0 & & $356(73)$ & 1759 (78) & 16.6 & \\
\hline Female & $187(12)$ & $1094(21)$ & 14.6 & & $233(68)$ & $1377(72)$ & 14.5 & & $174(72)$ & $1084(76)$ & 13.8 & \\
\hline Nationality & & & & $<0.001$ & & & & $<0.001$ & & & & 0.05 \\
\hline Norwegian & $345(18)$ & $1372(25)$ & 20.1 & & $391(70)$ & $1815(75)$ & 17.7 & & $320(75)$ & $1580(79)$ & 16.8 & \\
\hline Swedish & 79 (16) & 555 (33) & 12.5 & & $104(71)$ & $556(74)$ & 15.8 & & $76(75)$ & $391(80)$ & 16.3 & \\
\hline Danish & $105(12)$ & $556(22)$ & 15.9 & & $101(70)$ & $789(73)$ & 11.3 & & $84(74)$ & $587(78)$ & 12.5 & \\
\hline Other & 45 (14) & $215(17)$ & 17.3 & & $72(65)$ & $333(68)$ & 17.8 & & $46(65)$ & $270(66)$ & 14.6 & \\
\hline Skiing ability & & & & $<0.001$ & & & & 0.04 & & & & 0.02 \\
\hline Expert & $108(20)$ & $340(29)$ & 24.1 & & $123(76)$ & $591(79)$ & 17.2 & & $94(82)$ & $451(85)$ & 17.2 & \\
\hline Good & $184(11)$ & $762(28)$ & 19.5 & & $195(71)$ & $956(75)$ & 16.9 & & $174(74)$ & $891(79)$ & 16.3 & \\
\hline Interm & $147(16)$ & $816(22)$ & 15.3 & & $199(67)$ & $1059(73)$ & 15.8 & & $132(67)$ & $833(77)$ & 13.7 & \\
\hline Beginner & $121(21)$ & 725 (24) & 14.3 & & $111(69)$ & 700 (72) & 13.7 & & 89 (85) & $572(77)$ & 13.5 & \\
\hline Location & & & & $<0.001$ & & & & 0.007 & & & & 0.023 \\
\hline On piste & $395(16$ & 2073 (24) & 16.0 & & $365(69)$ & $2147(72)$ & 14.5 & & $295(78)$ & $1740(76)$ & 14.5 & \\
\hline Off-piste & $52(17)$ & $260(31)$ & 16.7 & & $82(82)$ & 373 (82) & 18.0 & & $41(69)$ & $283(83)$ & 12.7 & \\
\hline Park area & 70 (11) & $192(35)$ & 26.7 & & $155(70)$ & $772(80)$ & 16.7 & & $155(76)$ & $687(81)$ & 18.4 & \\
\hline Lift & $38(22)$ & 104 (34) & 23.0 & & $35(80)$ & $104(75)$ & 25.1 & & $26(72)$ & $92(81)$ & 21.6 & \\
\hline Equipment & & & & 0.49 & & & & 0.97 & & & & 0.03 \\
\hline Alpine & $287(20)$ & $1320(26)$ & 17.9 & & $432(75)$ & $2278(77)$ & 15.9 & & $381((79)$ & 1916 (84) & 16.6 & \\
\hline Snowboard & $245(12)$ & $1146(25)$ & 17.6 & & $184(65)$ & $981(70)$ & 15.8 & & $122(70)$ & $817(75)$ & 13.0 & \\
\hline Telemark & $32(3)$ & 147 (17) & 17.9 & & 14 (71) & $80(72)$ & 14.9 & & $11(40)$ & 49 (82) & 18.3 & \\
\hline $\begin{array}{l}\text { Rented } \\
\text { equipment }\end{array}$ & & & & 0.02 & & & & 0.13 & & & & 0.26 \\
\hline Yes & $162(18)$ & $896(24)$ & 15.3 & & $171(72)$ & 1009 (74) & 14.5 & & $140(82)$ & $835(80)$ & 14.4 & \\
\hline No & 400 (15) & $1743(26)$ & 18.7 & & $443(73)$ & $2250(75)$ & 16.5 & & $352(80)$ & $1851(81)$ & 16.0 & \\
\hline $\begin{array}{l}\text { Skiing } \\
\text { instruction }\end{array}$ & & & & 1.00 & & & & 0.14 & & & & 0.65 \\
\hline Yes & $180(17)$ & $838(29)$ & 17.7 & & $151(75)$ & $912(82)$ & 14.2 & & $134(89)$ & $720(87)$ & 15.7 & \\
\hline No & $362(15)$ & $1691(23)$ & 17.6 & & $402(73)$ & $2081(71)$ & 16.2 & & $303(75)$ & $1718(77)$ & 15.0 & \\
\hline
\end{tabular}

${ }^{*} p$ Values are shown for Fisher's exact test between the head injured and control groups.

tNumbers in parentheses represent the percentage with a helmet in the case and control groups, respectively. The column percentages represent the proportion of total cases (sum of controls and cases) with known helmet use that suffered a head injury.

In table 3, we compare potential risk factors for potentially severe head injuries. Of the 1781 head injuries recorded, 925 were classified as potentially severe, 262 in 2002 (45.3\%), 387 in 2010 (56.2\%) and 276 in 2011 (52.1\%). In 2002, wearing a helmet improved the odds for potentially severe head injuries (OR: $0.50,95 \%$ CI 0.35 to.70, $\mathrm{p}<0.001$ ); this effect was attenuated in 2010 (OR: $0.70,95 \%$ CI 0.62 to $0.85, \mathrm{p}<0.001$ ), and 2011 (OR: $0.77,95 \%$ CI 0.56 to $1.00, p=0.06$ ). There was a higher proportion of potentially severe head injuries in injured older skiers and snowboarders (>13 years) compared to younger (OR: 1.57 in $2002,95 \%$ CI 1.01 to $0.2 .45, p=0.04$; OR: 1.77 in $2010,95 \%$ CI 1.27 to $2.46, \mathrm{p}<0.001$; OR: 1.20 in $2011,95 \%$ CI 0.97 to $1.64, \mathrm{p}=0.32$ ). Also, skiing ability seems to be associated with the odds for potentially severe head injuries, with good and expert skiers and snowboarders consistently having worse odds (OR: 1.38 in 2002, 95\% CI 0.1 .07 to
$0.1 .79, \mathrm{p}<0.01)$; in $2010: 1.25,95 \%$ CI 1.01 to $1.54, \mathrm{p}<0.05$; (OR: 1.66 in $2011,95 \%$ CI 1.09 to $2.56 . p=0.01$ ).

Table 4 shows the relationship between participant characteristics and odds for head injuries in 2001, 2010 and 2011 analysed using multiple logistic regression analyses. Helmet use was associated with favourable odds for head injuries (OR: 0.45, 95\% CI 0.34 to $0.60 ; \mathrm{p}<0.001)$ in 2002 ; this effect was attenuated in 2010 (OR: $0.79,95 \%$ CI 0.63 to 0.98 ; $p=0.02$ ), and not significant in 2011 (OR: $0.80,95 \%$ CI 0.60 to 1.06 ; $\mathrm{p}=0.12$ ), when adjusted for potential confounders (age, sex, nationality, skiing ability, location and equipment). The test of interaction between helmet use and study year was statistically significant $(p=0.001)$. The associations with age, gender and ability were also weakened.

For potentially severe head injuries, the protective effect of using a helmet was better sustained over the observation period, 
Table 3 Univariate comparison of relationship between candidate risk factor and cases with potentially severe head injuries

\begin{tabular}{|c|c|c|c|c|c|c|c|c|c|}
\hline & \multicolumn{3}{|c|}{$2002(262 / 3276)$} & \multicolumn{3}{|c|}{$2010(387 / 4396)$} & \multicolumn{3}{|c|}{$2011(276 / 3436)$} \\
\hline & Cases (n) & Per cent & $\mathrm{p}$ Value & Cases (n) & Per cent & $\mathrm{p}$ Value & Cases (n) & Per cent & p Value \\
\hline Helmet use & & & $<0.001$ & & & $<0.001$ & & & 0.06 \\
\hline Yes & 37 (14) & 4.7 & & $247(63)$ & 8.3 & & $201(73)$ & 7.7 & \\
\hline No & 223 & 9.1 & & 124 & 12.6 & & 64 & 10.0 & \\
\hline Age & & & 0.09 & & & $<0.001$ & & & 0.68 \\
\hline$<13$ & $25(72)$ & 5.5 & & $46(97)$ & 6.9 & & $43(95)$ & 7.7 & \\
\hline $13-20$ & $116(9)$ & 8.3 & & $118(82)$ & 7.8 & & $105(81)$ & 7.4 & \\
\hline$>20$ & $117(7)$ & 8.4 & & 209 (54) & 11.6 & & $117(60)$ & 9.1 & \\
\hline Gender & & & $<0.001$ & & & 0.13 & & & 0.05 \\
\hline Male & $187(16)$ & 9.5 & & $247(68)$ & 9.5 & & $186(72)$ & 8.8 & \\
\hline Female & $75(10)$ & 5.9 & & $137(72)$ & 8.5 & & $90(60)$ & 7.2 & \\
\hline Nationality & & & 0.003 & & & $<0.001$ & & & 0.008 \\
\hline Norwegian & $161(16)$ & 9.4 & & $216(65)$ & 9.8 & & 157 (75) & 8.3 & \\
\hline Swedish & $35(8)$ & 5.5 & & 70 (69) & 10.6 & & $48(73)$ & 10.3 & \\
\hline Danish & $41(7)$ & 6.2 & & $50(64)$ & 5.6 & & $(44 / 65)$ & 6.6 & \\
\hline Other & $25(24)$ & 9.6 & & $50(76)$ & 12.3 & & $27(62)$ & 8.5 & \\
\hline Skiing ability & & & 0.004 & & & 0.20 & & & 0.002 \\
\hline Expert & $48(21)$ & 10.7 & & $72(84)$ & 10.1 & & $53(80)$ & 9.7 & \\
\hline Good & $90(10)$ & 9.5 & & $111(79)$ & 9.6 & & $100(73)$ & 9.4 & \\
\hline Intermediate & $69(11)$ & 7.2 & & $116(60)$ & 9.2 & & $65(72)$ & 6.7 & \\
\hline Beginner & $50(18)$ & 5.9 & & $67(46)$ & 8.2 & & $40(65)$ & 6.1 & \\
\hline Equipment & & & 0.55 & & & 0.73 & & & 0.07 \\
\hline Alpine & $120(15)$ & 7.5 & & $250(68)$ & 9.2 & & $200(72)$ & 8.7 & \\
\hline Snowboard & $121(13)$ & 8.7 & & $102(73)$ & 8.8 & & $61(71)$ & 6.5 & \\
\hline Telemark & $15(0)$ & 8.4 & & $11(70)$ & 11.8 & & $8(65)$ & 13.3 & \\
\hline Location & & & $<0.005$ & & & 0.02 & & & $<0.001$ \\
\hline On piste & $189(13)$ & 7.6 & & $210(62)$ & 8.4 & & $142(67)$ & 5.3 & \\
\hline Park area & $33(6)$ & 12.6 & & $92(85)$ & 9.9 & & 97 (78) & 11.5 & \\
\hline Off-piste & $18(17)$ & 5.7 & & $52(75)$ & 11.4 & & $22(74)$ & 6.8 & \\
\hline Lift & $16(0)$ & 11.3 & & $16(75)$ & 11.5 & & $11(72)$ & 9.3 & \\
\hline Rented equipment & & & 0.08 & & & 0.11 & & & 0.04 \\
\hline Yes & $72(17)$ & 6.8 & & $98(71)$ & 8.3 & & $64(81)$ & 6.6 & \\
\hline No & $185(12)$ & 8.6 & & $258(77)$ & 9.6 & & $192(81)$ & 8.7 & \\
\hline Skiing instruction & & & 0.13 & & & 0.01 & & & 0.21 \\
\hline Yes & 70 (14) & 6.9 & & 77 (73) & 7.2 & & $74(85)$ & 8.7 & \\
\hline No & $173(12)$ & 8.4 & & $241(72)$ & 9.7 & & $156(78)$ & 7.7 & \\
\hline
\end{tabular}

* $p$ Values are from Fisher's exact tests comparing skiers with and without each of the factors.

tNumbers in parentheses represent the percentage with a helmet in the case and control groups, respectively. The column percentages represent the proportion of total cases (sum of controls and cases) with known helmet use that suffered a potentially severe head injury.

from an OR of 0.44 (95\% CI 0.28 to $0.68, \mathrm{p}<0.001)$ in 2002 to an OR of $0.74(95 \%$ CI 0.57 to $0.97, \mathrm{p}=0.02)$ in 2010 and 0.67 (95\% CI 0.47 to $0.96 ; p=0.03$ ) in 2011 , adjusted for the same potential confounders (table 5). The test of interaction between helmet use and study year was statistically significant $(p=0.038)$. The gender difference was attenuated during the same period. The location of the incident seemed to matter, with worse odds for potentially severe head injuries in park areas compared to groomed slopes (table 5).

\section{DISCUSSION}

The main finding of this study was that helmet use among injured skiers and snowboarders has increased more than threefold from $2002(23.8 \%)$ to 2011 (77.1\%), but that the relative reduction in the proportion of head injuries over the same period was smaller than anticipated (from $17.6 \%$ to $15.4 \%$ ). Also, the results show that the helmet effect was attenuated over the decade in question; the OR for head injury when the skier or snowboarder wore a helmet was reduced by $55 \%$ in 2002 compared to only $21 \%$ and $20 \%$ in 2010 and 2011 .

Recent decades have seen dramatic changes in alpine skiing equipment, especially with the carving skis and twin-tip skis, opening new possibilities for acrobatic skiing moves, possibly with increased injury risk. ${ }^{15}$ The park areas have gone through an extreme development over the past decade, high jumps and other obstacles raising concerns about the potential for severe injuries from high-impact crashes. Our data document an increase in the number and proportion of injured persons in park areas from $8 \%$ in 2002 to $21 \%$ and $25 \%$ in 2010 and 2011. In the same period, the proportion of expert and good skiers has increased. Therefore, it is possible that an increased number of skilled skiers performing more risky moves has led to an increased injury risk in snow parks over the observed decade.

The study shows that the likelihood of potentially severe head injuries by location was greater in snow parks relative to other areas, and does not appear to have changed much over the 
Table 4 Multiple logistic regression analyses of relationship between head injuries and potential risk factors in 2002,2010 and 2011

\begin{tabular}{|c|c|c|c|c|c|c|}
\hline & \multicolumn{2}{|l|}{$2002(578 / 3276)$} & \multicolumn{2}{|l|}{$2010(673 / 4396)$} & \multicolumn{2}{|l|}{$2011(530 / 3436)$} \\
\hline & OR (95\% Cl) & $p$ Value & OR $(95 \% \mathrm{Cl})$ & p Value & OR $(95 \% \mathrm{Cl})$ & p Value \\
\hline Helmet use & & $<0.001$ & & 0.02 & & 0.13 \\
\hline No & 1 & & 1 & & 1 & \\
\hline Yes & $0.45(0.34$ to 0.60$)$ & & 0.79 (0.63 to 0.98$)$ & & $0.80(0.60$ to 1.06$)$ & \\
\hline Age & & 0.002 & & 0.03 & & 0.78 \\
\hline$<13$ & 1 & & 1 & & 1 & \\
\hline $13-20$ & $0.69(0.49$ to 0.96$)$ & & $0.80(0.61$ to 1.06$)$ & & $0.89(0.65$ to 1.23$)$ & \\
\hline$>20$ & 0.55 (0.39 to 0.78$)$ & & $0.90(0.68$ to 1.20$)$ & & $0.93(0.66$ to 1.29$)$ & \\
\hline Gender & & 0.003 & & 0.02 & & 0.10 \\
\hline Male & 1 & & 1 & & 1 & \\
\hline Female & $0.72(0.59$ to 0.90$)$ & & $0.78(0.64$ to 0.95$)$ & & 0.89 (0.65 to 1.22$)$ & \\
\hline Nationality & & 0.002 & & 0.006 & & 0.02 \\
\hline Norwegian & 1 & & 1 & & 1 & \\
\hline Swedish & $0.58(0.44$ to 0.77$)$ & & $0.90(0.70$ to 1.17$)$ & & $0.98(0.72$ to 1.35$)$ & \\
\hline Danish & 0.80 (0.61 to 1.06$)$ & & $0.62(0.47$ to 0.81$)$ & & $0.70(0.49$ to 0.99$)$ & \\
\hline Other & 0.78 (0.53 to 1.14$)$ & & 0.95 (0.69 to 1.13$)$ & & 0.82 (0.65 to 1.04$)$ & \\
\hline Ability & & $<0.001$ & & 0.77 & & 0.32 \\
\hline Expert & 1 & & 1 & & 1 & \\
\hline Good & $0.78(0.58$ to 1.03$)$ & & 1.13 (0.80 to 1.37$)$ & & $1.01(0.74$ to 1.37$)$ & \\
\hline Intermediate & $0.55(0.41$ to 0.75$)$ & & 1.02 (0.77 to 1.34$)$ & & 0.73 (0.56 to 0.94$)$ & \\
\hline Beginner & 0.55 (0.39 to 0.76$)$ & & $0.91(0.65$ to 1.25$)$ & & 0.92 (0.61 to 1.37$)$ & \\
\hline Location & & $<0.005$ & & 0.03 & & 0.17 \\
\hline On piste & 1 & & 1 & & 1 & \\
\hline Off-piste & 0.96 (0.69 to 1.34$)$ & & 0.95 (0.74 to 1.24$)$ & & 0.77 (0.53 to 1.13$)$ & \\
\hline Park area & 1.80 (1.30 to 2.48$)$ & & 1.18 (0.88 to 1.58$)$ & & 1.16 (0.90 to 1.50$)$ & \\
\hline Lift & 1.94 (1.04 to 3.65$)$ & & 2.35 (1.06 to 5.26$)$ & & 1.47 (0.63 to 3.42$)$ & \\
\hline Equipment & & 0.12 & & 0.12 & & 0.04 \\
\hline Alpine & 1 & & 1 & & 1 & \\
\hline Snowboard & 0.79 (0.63 to 0.98$)$ & & $0.90(0.73$ to 1.14$)$ & & $0.72(0.56$ to 0.94$)$ & \\
\hline Telemark & $0.61(0.45$ to 1.06$)$ & & 0.75 (0.39 to 1.42$)$ & & 0.90 (0.41 to 1.98$)$ & \\
\hline
\end{tabular}

years. So, despite the trend for higher relative injury risks in park areas, the risk of head injury cases compared to controls over the actual period decreased. We observed a similar trend with an increased proportion of injured alpine skiers, while the proportion of alpine skiers with head injury was relatively stable over the same period. In other words, park areas appear to have become safer in terms of head injuries, while they are getting less safe generally. This apparent disassociation may be the result of the large increase in the proportion of helmeted skiers and snowboarders. However, it should be noted that all these changes are relative within the injured population. Further studies are necessary to classify injury patterns in the parks, and continuous preventive efforts are needed to limit injury severity.

More injured skiers and snowboarders classified themselves as good or expert in 2010 and 2011 than in 2002. In our previous study, ${ }^{3}$ we asked control skiers and snowboarders about risktaking behaviour, and compared it with helmet wear. We saw that expert skiers and risk-takers were more likely to wear a helmet. A study by Buller et $a l^{16}$ found that the highest proportion with helmets was among expert skiers and snowboarders. Ružić and Tudor ${ }^{17}$ also made similar observations, while others have found no evidence of risk compensation among helmet wearers. ${ }^{18} 19$ Mueller et $a l^{9}$ found a poor helmet correlation among head-injured grown female skiers, indicating that helmeted skiers continue to take risks, while unhelmeted skiers gradually ski less risky. If this were a factor in our study, it could help explain the results, as it would lead to a higher injury rate among helmet users and even the attenuated gender difference in injury risk observed over the decade.

In our study, we observed a trend that severe head injuries occurred more frequently in adult skiers and snowboarders. In 2010 and 2011, potentially severe head injuries occurred more often among Norwegian and Swedish skiers than Danish skiers, possibly because the latter are less skilled and ski more cautiously. Thus, skiing ability also seems to be associated with risk of potential severe head injuries, with the good and expert skiers and snowboarders at highest risk.

We have conducted the study in the same skiing areas, and the ski patrol registration system remains the same, as well as the injury registration form used. Recall bias is not likely, since the ski patrol made the injury interviews on the spot, typically only a few minutes after the injury occurred. Nevertheless, except for skiing ability, ${ }^{20}$ we have not carried out any reliability studies, so we do not know the degree of misclassification errors. Although we do not know how a stressful injury situation may have affected how skiers reported their skiing ability or skiing instruction, most other factors (including helmet status) could be observed directly by the ski patrol.

Still, there are some issues that should be borne in mind when interpreting the results of the current study. One limitation is that we used skiers and snowboarders with other injuries as controls, as was done in most previous studies to estimate the 
Table 5 Multiple logistic regression analyses of relationship between potentially severe head injuries and potential risk factors in 2002,2010 and 2011

\begin{tabular}{|c|c|c|c|c|c|c|}
\hline & \multicolumn{2}{|l|}{$2002(262 / 3276)$} & \multicolumn{2}{|l|}{$2010(387 / 4396)$} & \multicolumn{2}{|l|}{$2011(276 / 3436)$} \\
\hline & OR $(95 \% \mathrm{Cl})$ & $p$ value & OR $(95 \% \mathrm{Cl})$ & $\mathrm{p}$ Value & OR $(95 \% \mathrm{Cl})$ & $\mathrm{p}$ Value \\
\hline Helmet use & & $<0.001$ & & 0.03 & & 0.03 \\
\hline No & 1 & & 1 & & 1 & \\
\hline Yes & 0.44 (0.28 to 0.68$)$ & & 0.74 (0.57 to 0.97$)$ & & $0.67(0.47$ to 0.96$)$ & \\
\hline Age & & 0.58 & & 0.003 & & 0.73 \\
\hline$<13$ & 1 & & 1 & & 1 & \\
\hline $13-20$ & 1.26 (0.71 to 2.24$)$ & & 1.02 (0.69 to 1.49$)$ & & 0.91 (0.59 to 1.40$)$ & \\
\hline$>20$ & 1.11 (0.62 to 1.98$)$ & & 1.16 (1.07 to 2.29$)$ & & 1.04 (0.66 to 1.64$)$ & \\
\hline Gender & & 0.003 & & 0.45 & & 0.30 \\
\hline Male & 1 & & 1 & & 1 & \\
\hline Female & 0.63 (0.46 to 0.86$)$ & & 0.83 (0.65 to 1.06$)$ & & 0.85 (0.62 to 1.15$)$ & \\
\hline Nationality & & 0.03 & & 0.001 & & 0.59 \\
\hline Norwegian & 1 & & 1 & & 1 & \\
\hline Swedish & 0.54 (0.35 to 0.83$)$ & & 1.1 (0.74 to 1.38$)$ & & $1.18(0.80$ to 1.76$)$ & \\
\hline Danish & 0.77 (0.50 to 1.21$)$ & & 0.49 (0.34 to 0.71$)$ & & $0.82(0.51$ to 1.13$)$ & \\
\hline Other & 1.00 (0.60 to 1.70$)$ & & 1.05 (0.68 to 1.52 ) & & 0.94 (0.53 to 1.63$)$ & \\
\hline Ability & & 0.12 & & 0.99 & & 0.29 \\
\hline Expert & 1 & & 1 & & 1 & \\
\hline Good & 0.93 (0.62 to 1.38$)$ & & 1.04 (0.75 to 1.44$)$ & & $1.17(0.78$ to 1.73$)$ & \\
\hline Intermediate & $0.68(0.44$ to 1.05$)$ & & 1.04 (0.74 to 1.46$)$ & & 0.82 (0.52 to 1.28$)$ & \\
\hline Beginner & 0.62 (0.38 to 1.03$)$ & & 1.02 (0.68 to 1.52$)$ & & 0.88 (0.51 to 1.53$)$ & \\
\hline Location & & 0.002 & & 0.05 & & 0.04 \\
\hline On piste & 1 & & 1 & & 1 & \\
\hline Off-piste & 0.65 (0.38 to 1.10$)$ & & 1.24 (0.90 to 1.69$)$ & & 0.85 (0.52 to 1.42$)$ & \\
\hline Park area & 1.41 (0.92 to 2.16$)$ & & 1.42 (1.00 to 2.05$)$ & & 1.58 (1.15 to 2.18$)$ & \\
\hline Lift & 2.50 (1.58 to 5.12$)$ & & $1.76(0.34$ to 3.97$)$ & & $1.21(0.45$ to 2.01$)$ & \\
\hline Equipment & & 0.62 & & 0.59 & & 0.13 \\
\hline Alpine & 1 & & 1 & & 1 & \\
\hline Snowboard & 0.88 (0.64 to 1.22$)$ & & 0.85 (0.66 to 1.11$)$ & & 0.69 (0.49 to 0.92$)$ & \\
\hline Telemark & 0.67 (0.36 to 1.24$)$ & & 0.92 (0.46 to 1.86$)$ & & $1.40(0.60$ to 3.25$)$ & \\
\hline
\end{tabular}

protective effect of cycling helmets, ${ }^{21}$ The assumption is that whether a fall causes injury to the head or to another body part is influenced by helmet status, and these injured groups can therefore be compared to assess the protective effect of the helmet. However, this estimate can be confounded by a number of other factors. In our previous study, ${ }^{3}$ we therefore also included an uninjured control group from the same skiing areas. When we compared the results between the injured and the uninjured control groups, the helmet effect was essentially the same. This lends support to the current risk estimates reported.

Head injuries combined with other injuries were rare $(2-3 \%$ of cases), but as these could potentially bias the helmet effect estimates, we also performed sensitivity analyses excluding these cases. There was essentially no change in the risk estimates reported (data not shown).

It would have been preferable to include data from all ski seasons between 2002 through 2011. Unfortunately, data for 2003 through 2009 were not available.

Another issue is the helmet quality. We have not tested or evaluated the helmets of the skiers or snowboarders in this study. Nevertheless, all helmets rented out or sold in Norway are CE-certified.

The large change in helmet use among injured people in the slopes was age-related. We observed an increase in helmet wear in our injured control group among skiers and snowboarders under the age of 13 from $70 \%$ to $96 \%$ over the decade, compared to from $22 \%$ to $84 \%$ for age 13 to 20 and from $15 \%$ to $66 \%$ for those over 20 years. We have adjusted for ability and age in our regression analyses, but it may be important to note that helmet wear was already high among children.

Research methods to assess the effect of protective equipment could be improved. Using exposure-adjusted injury rates would be valuable. Better quality medical injury data are desirable. This could be achieved by better medical education of ski patrol, as well as better cooperation with local hospitals for medical data exchange. Injury forms should be adapted to capture new trends in skiing and snowboarding, as well as information on new injury patterns. Hypotheses around behavioural change and helmet impact performance represent potential areas for future research. Capturing injury-free accidents could also provide important information.

In conclusion, even if the reduction in the proportion of head injuries was smaller than expected, there was a reduction. Also, the results show that, although less pronounced than in 2002, the risk of head injuries, at least of potentially severe head injuries, was still reduced among helmet users in 2011. Therefore, wearing a helmet should be strongly recommended. 


\section{What are the findings?}

This study demonstrated an attenuated association between helmet use and risk of head injury among injured skiers and snowboarders after a decade when the vast majority had begun wearing helmets.

\section{How might it impact on clinical practice in the future?}

Clinicians as well as the skiing resorts and ski rentals should inform skiers and snowboarders that current helmets have a limited capacity to protect the head. Skiers and snowboarders must remain aware of the risks of head injury associated with the decisions they make while skiing, thus skiing according to their capacity and skill as well as the piste challenges they encounter.

Acknowledgements The authors are indebted to Andreas Rødven, General Secretary of the Norwegian Ski Lift Association and the ski patrols at the various resorts for recording injuries.

Contributors SS and IH have performed the statistical analyses. SS have written the article, and RB and AE have contributed in preparing the manuscript for submission. The Norwegian Ski Patrols at the various resorts have recorded the injuries.

Funding The Oslo Sports Trauma Research Center has been established at the Norwegian School of Sport Sciences through grants from the Norwegian Eastern Health Corporatie, the Royal Norwegian Ministry of Culture, the Norwegian Olympic Committee and Confederation of Sport, the International Olympic Committee, and Norsk Tipping AS. Data collection was funded by the Norwegian Ski Lift Association. Helse Sør-Øst RHF.

Competing interests None declared.

Ethics approval The study was based on anonymised data from the Norwegian Ski Lift Association injury and marketing research databases, and the Regional Committee for Medical Research Ethics did not require ethical approval.

Provenance and peer review Not commissioned; externally peer reviewed.

\section{REFERENCES}

1 Haid B. [Fatal ski injuries in the area surrounding the Chirurgishen Universitäts-Klinik Innspruck, 1944 to 1945]. Arch Ortop Unfallchir 1955;47:105-14.

2 Oh S, Schmid UD. [Head-injuries in childhood caused by skiing accidents and optimal prevention]. Z Kinderchir 1983;38:66-72.

3 Sulheim S, Ekeland A, Holme I, et al. Helmet use and risk of head injuries in alpine skiers and snowboarders. JAMA 2006;295:919-24.

4 Hagel BE, Pless IB, Goulet C, et al. Effectiveness of helmets in skiers and snowboarders: case-control and case crossover study. BMJ 2005;330:281.

5 Macnab AJ, Smith T, Gagnon FA, et al. Effect of helmet wear on the incidence of head/face and cervical spine injuries in young skiers and snowboarders. Inj Prev 2002:8:324-7.

6 Cusimano MD, Kwok J. The effectiveness of helmet wear in skiers and snowboarders: a systematic review. Br I Sports Med 2010;44:781-6.

7 Haider AH, Saleem T, Bilaniuk JW, et al., Eastern Association for the Surgery of Trauma Injury ControlViolence Prevention Committee. An evidence-based review: Efficacy of safety helmets in the reduction of head injuries in recreational skiers and snowboarders. J Trauma Acute Care Surg 2012;73:1340-7.

8 Ruedl G, Kopp M, Burtscher M. The protective effects of helmets in skiers and snowboarders. BMJ 2011;342:d857.

9 Mueller BA, Cummings P, Rivara FP, et al. Injuries of the head, face, and neck in relation to ski helmet use. Epidemiology 2008;19:270-6.

10 Greve MW, Young DJ, Goss AL, et al. Skiing and snowboarding head injuries in 2 areas of the United States. Wilderness Environ Med 2009;20:234-8.

11 Rhugani Al, Lin CT, Ares WJ, et al. Helmet use and reduction in skull fractures in skiers and snowboarders admitted to the hospital. J Neurosurg Pediatr 2011;7:268-71.

12 Hagel BE, Russell K, Goulet C, et al. Helmet use and risk of neck injury in skiers and snowboarders. Am J Epidemiol 2010;171:1134-43.

13 Russell K, Christie J, Hagel BE. The effect of helmets on the risk of head and neck injuries among skiers and snowboarders: a meta-analysis. CMAJ 2010;182:333-40.

14 Byrd D. Skier/Snowboarder Fatality Incidents During 2013-14 Season. http://www. nsaa.org

15 Brooks AM, Evans MD, Rivara FP. Evaluation of skiing and snowboarding injuries sustained in terrain parks versus traditional slopes. Inj Prev 2010;16:119-22.

16 Buller DB, Andersen PA, Walkosz BJ, et al. The prevalence and predictors of helmet use by skiers and snowboarders at ski areas in western North America in 2001. J Trauma 2003;55:939-45.

17 Ružić L, Tudor A. Risk-taking behavior in skiing among helmet wearers and nonwearers. Wilderness Environ Med 2011;22:291-6.

18 Scott MD, Buller DB, Andersen PA, et al. Testing the risk compensation hypothesis for safety helmets in alpine skiing and snowboarding. Inj Prev 2007;13:173-7.

19 Hagel B, Pless IB, Goulet C, et al. The effect of helmet use on injury severity and crash circumstances in skiers and snowboarders. Accid Anal Prev 2005;37:103-8.

20 Sulheim S, Skeland A, Bahr R. Self-estimation of ability among skiers and snowboarders in alpine skiing resorts. Knee Surg Sports Traumatol Arthrosc 2007;15:665-70.

21 Thompson DC, Rivara FP, Thompson R. Helmets for preventing head and facial injuries in bicyclists. Cochrane Database Syst Rev 2000(2):CD001855. 